\title{
Probabilistic Assessment of Monthly River Flow Discharge Using Copula And OSVR Approaches
}

Mohammad Nazeri Tahroudi ( $\Delta$ m_nazeri2007@yahoo.com )

University of Birjand https://orcid.org/0000-0002-6871-2771

Rasoul Mirabbasi

Shahrekord University

Yousef Ramezani

University of Birjand

Farshad Ahmadi

Shahid Chamran University of Ahvaz

\section{Research Article}

Keywords: ARCH Models, ARMA, Conditional heteroscedasticity, Copula-GARCH, Rainfall- Runoff Modeling

Posted Date: June 3rd, 2021

DOl: https://doi.org/10.21203/rs.3.rs-440240/v1

License: (1) (1) This work is licensed under a Creative Commons Attribution 4.0 International License. Read Full License 
Probabilistic assessment of monthly river flow discharge using copula and OSVR approaches

4 Mohammad Nazeri Tahroudi ${ }^{*}$, Rasoul Mirabbasi ${ }^{2}$, Yousef Ramezani $^{3}$, Farshad Ahmadi $^{4}$ 5 1. Ph.D Candidate, Department of Water Engineering, University of Birjand, Birjand, Iran.

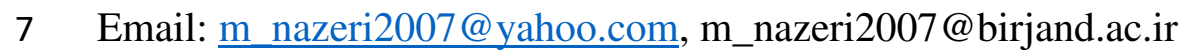

2. Associate Professor, Department of Water Engineering, Shahrekord University, $9 \quad$ Shahrekord, Iran, Email: mirabbasi@agr.sku.ac.ir 3. Associate Professor, Department of Water Engineering, University of Birjand, Birjand, 11 Iran. Email: y.ramezani@birjand.ac.ir

12 4-Assistant Professor, Department of Hydrology and Water Management, Shahid Chamran 13 University of Ahvaz, Ahvaz, Iran. Email: f.ahmadi@scu.ac.ir

$14 \quad *$ Corresponding Author 
Probabilistic assessment of monthly river flow discharge using copula and OSVR

approaches

important issues in hydrology and water resources studies, especially in areas where data with the

shorter time scales are not available. In this study, the applicability of support vector regression

(SVR) model optimized by Ant colony and Copula-GARCH algorithms was investigated and compared to simulate the flow discharge based on total monthly rainfall in Talezang Basin, Iran.

Entropy theory was used to select a suitable meteorological station corresponding to a hydrometric

station. The vector autoregressive model was also used as the base model in Copula-GARCH simulations. The correlation results of the studied paired variable confirmed the possibility of using copula-based models. The simulation results were evaluated using $\mathrm{R}^{2}$, Nash-Sutcliffe Efficiency (NSE) and root mean square error (RMSE) statistics. According to the $99 \%$ confidence intervals of the simulations, the accuracy of both models was confirmed. The simulation results showed that the Copula-GARCH model was more accurate than the optimized SVR (OSVR) model.

31 Considering the $90 \%$ efficiency $(\mathrm{NSE}=0.90)$ of Copula-GARCH approach, the results show a

$3236 \%$ improvement of RMSE statistics by Copula-GARCH model compared to OSVR model in

33 simulating the flow discharge on a monthly scale. The results also showed that by combining nonlinear ARCH models with the copula-based simulations, the reliability of the simulation results increases, which was also confirmed using the violin plot. The results also showed an increase in the accuracy of the Copula-GARCH model at the minimum and maximum values of the data. Keywords: ARCH Models, ARMA, Conditional heteroscedasticity, Copula-GARCH, Rainfall- 


\section{Introduction}

River flow discharge as an input to water resources systems is one of the important parameters

41 in managing the operation of dam reservoirs. Simulation and forecasting the annual discharge can

42 be done using stochastic methods. On a monthly scale, which is more important in dam

43 management, due to the seasonal and periodic approach of stochastic methods, the number of

44 parameters increases and as a result, the estimation error will be increased. Therefore, by including

45 other effective parameters in discharge values, the accuracy of the simulations can be increased.

46 Accurate calculation of flow discharge and flood is a special priority for many river engineering

47 and flood control projects. On the other hand, various studies in different parts of Iran indicate the

48 occurrence of climate change and changes in meteorological parameters in recent decades

49 (Ramezani and Tahroudi, 2020). This will also have a more impact on the flow discharge.

50 Meteorological studies also show that changes in precipitation pattern in different parts of Iran are

51 irregular. These changes have increased the frequency of extreme events, especially precipitation

52 and it led to increase the maximum runoff occurrences. Since the design of most dams in the

53 country does not take into account the conditions of climate change and the occurrence of such

54 rainfalls, usually the runoff from these rainfalls is not stored and becomes unavailable as floods

55 (Ramezani et al. 2020; Tahroudi et al. 2019 a \& b; Khozeymehnezhad and Tahroudi, 2019). River

56 flow discharge is also affected by base flow and rainfall in each region. Simulation of flow

57 discharge given by rainfall will greatly assist in the water resources management and flood control

58 in catchments. In addition to the importance of modeling and simulations in estimation of flow

59 discharge, sometimes different simulation models are used to overcome the problem of data

60 shortage or lack of data on a short time scale. One of the most widely approaches in this field is

61 using the linear time series models. One of the most important models of this family is vector 
62 autoregressive (VAR) models that are able to model several time series with different delays.

63 Using these models, the effect of different variables on each other or the simultaneous effect of a

64 particular variable in several stations can be examined.

65 The VAR model is one of the linear time series models that can be combined with nonlinear 66 models and the residuals of these models can be considered and modeled. The most important 67 nonlinear models are autoregressive conditional heteroscedasticity $(\mathrm{ARCH})$ family models such as generalized autoregressive conditional heteroskedasticity (GARCH) model. These models have 69 a high ability to connect with the residuals of the linear models. In most cases, while combining 70 with linear models, they have increased the accuracy of calculations. Recent developments in the 71 use of copula functions and their integration with non-linear ARCH models have led to new 72 research that the effect of various parameters can be considered in terms of multivariate analysis 73 based on the copula function. Copulas are functions that create a multivariate distribution function 74 by connecting univariate margin functions (Nelsen, 2006; Sklar, 1959). Separate analysis of 75 marginal distributions and their dependence structure is one of the most important advantages of 76 copula functions (Serinaldi et al. 2009; Salvadori et al. 2007; Ramezani et al. 2019). In recent 77 years, the use of hybrid models and copula based models for simulations has attracted the attention 78 of researchers. Using the Copula-GARCH approach, Yoo et al. (2016) analyzed and simulated 79 precipitation values at 12 rain gauge stations in South Korea. The results showed that the proposed 80 method will be very effective in quantifying the uncertainty of bivariate drought frequency curves. 81 Various studies can also be mentioned in this field (Li and Zheng, 2016; Guo and Wang, 2017;

82 Abdi et al. 2017; Ayantobo et al. 2018; Kim et al. 2019). Yuan et al (2020) used the Copula83 GARCH approach to study price fluctuations in agricultural commodities. Their results showed 84 that the proposed approach has a high ability to describe the interaction of parameters with each 
85 other. Tahroudi et al. (2020a) investigated the changes and joint frequency analysis of 86 meteorological and hydrological droughts in the Zarrineh-Rud catchment in the south of Lake

87 Urmia in Iran using copula functions. The results showed that by using copula functions, for a 88 specific meteorological drought duration in a station, the duration of hydrological drought in an 89 existing hydrometric station can be determined based on the probability of conditional occurrence 90 as well as certain return periods. Tahroudi et al. (2020b) analyzed the conditional and joint 91 behavior of groundwater level deficiency and rainfall deficiency signature in the Naqadeh sub92 basin located in the Lake Urmia Basin in Iran using copula functions. Considering the maximum 93 groundwater level deficiency produced, the relationship between rainfall deficiency and 94 groundwater level deficiency was obtained to estimate the groundwater level deficiency signature 95 values. In addition to the proposed approaches that have been used recently, there are various other models in this field, which can be referred to as support vector machine models, regression-based

97 models, genetic programing, etc. The optimized support vector regression (OSVR) method has 98 high efficiency in simulating meteorological and hydrological parameters, which has been 99 mentioned in the studies of Tahroudi and Ramezani (2020). Optimizing the parameters of the 100 support vector regression method using various algorithms such as the ant colony improves the 101 performance and accuracy of the model in the simulations. Nazeri Tahroudi and Ramezani (2020) 102 simulate the dew point temperature values in different climates of Iran by optimizing the 103 parameters of the support vector regression model. Copula-based simulation and simulation based 104 on OSVR are both optimized and enhanced models, that the first model can be upgraded using the 105 GARCH nonlinear model and the second one can be upgraded using optimization algorithms such 106 as the ant colony optimization (ACO) algorithm. With the simulation approach based on the 107 Copula-GARCH hybrid model, the values obtained from the bivariate frequency curve will be 


\section{Material and Methods}

\subsection{Case Study}

Dez basin is located between two meridians of eastern $48^{\circ}, 10^{\prime}$ and $50^{\circ}, 21^{\prime}$ and two orbits of northern $31^{\circ}, 34^{\prime}$ and $34^{\circ}, 7^{\prime}$ in the western regions of Iran. The area of this basin is equal to 21720 square kilometers and have an average elevation 1600 meters above mean sea level. In this study, Copula-GARCH and OSVR models were used for modeling the monthly rainfall-runoff in the mentioned basin. The data used belong to the Dez basin at the Talezang hydrometric station in the period 1988-2018. Fig 1 shows the location of the studied basin and its hydrometric and rain gauge stations. The summery of statistical characteristics of the studied data are also presented in Table 1.
Fig. 1.

\section{Table 1.}




\subsection{Kendall's tau correlation}

The first step in copula-based analysis is to examine the dependence structure between the studied variables. The usual method for examining correlation is the Kendall's tau correlation coefficient. The Kendall's tau, denoted by $\tau$, is defined as the probability of concordance minus the probability of discordance between the two paired random variables $\mathrm{X}_{1}$ and $\mathrm{X}_{2}$. The Kendall's tau value between the continuous random variables $\mathrm{X}_{1}$ and $\mathrm{X}_{2}$ is defined as Equation (1):

$$
\tau\left(X_{1}, X_{2}\right)=P\left(\left(X_{11}-X_{21}\right)\left(X_{12}-X_{22}\right)>0\right)-P\left(\left(X_{11}-X_{21}\right)\left(X_{12}-X_{22}\right)<0\right)
$$

where, $\left(X_{11}-X_{12}\right)$ and $\left(X_{21}-X_{22}\right)$ are independent and regular distributed differences of $\left(X_{1}, X_{2}\right)$ (Hollander et al. 2014).

\subsection{Vector Autoregressive (VAR) Models}

VAR is one of the flexible models for analyzing the multivariate time series. The VAR model was introduced to describe the dynamic behavior of the economic and financial series and their prediction. VAR model predictions are quite flexible, since they can bet on the future path of potential variables. In addition to describing and forecasting data, the VAR model is also used for structural inferences and analyzing the policies. In structural analysis, specific hypotheses are imposed on the structure of the data under investigation, and the effects of unexpected shocks or innovations are summed up with the model variables. These effects are usually summarized with impact reaction and predicted error variance analysis functions. This model focuses on the analysis of constant multivariate covariance. VAR models in economic analysis have been introduced by Sims (1980). In this study, the base model was selected to create the Copula-GARCH model, is a VAR model. This model has been selected according to the number of studied parameters and their dependencies. For more information, see Shahidi et al. (2020). 


\subsection{Autoregressive model with conditional heteroskedasticity}

The GARCH model was developed as an alternative to time series models that, based on the assumption of linearity between variables at different time stages, could not take into account the

157 conditional dependence of the variance or heteroskedasticity. Because of its power in modeling 158 variables in which changes are significant, it has been widely used, especially in the financial and 159 economic fields (Duan, 1996; Tse and Tsui, 2002; Floros et al. 2007; Watanabe, 2012). The 160 GARCH model has many applications in hydrological time series simulation (Wang et al. 2005; 161 Modarres and Ouarda, 2012; Yusef and Kane, 2012; Ramezani et al. 2019). In this paper, the 162 GARCH model is developed to detect heteroskedasticity in the flow discharge time series. The 163 parameters of the GARCH model were estimated using the maximum likelihood method. introduced and developed in economic studies by Engle (1982). All different modes of this model 166 are based on the ARCH model. In general, the ARCH model is as follows:

$$
\varepsilon_{t}=\sigma_{t} z_{t} \quad \text { and } \quad \sigma_{t}^{2}=a_{0}+\sum_{i=1}^{m} b_{i} \varepsilon_{t-i}^{2}
$$

$$
a_{t}=\sigma_{t} \varepsilon_{t}, \sigma_{t}^{2}=a_{0}+a_{1} a_{t-1}^{2}
$$

171 where, $a_{1} \geq 0, a_{0} \geq 0$. First of all, the conditional mean $a_{t}$ must be zero. Because:

$$
E\left(a_{t}\right)=E\left[E\left(a_{t} \mid F_{t-1}\right)\right]=E\left[\sigma_{t} E\left(\varepsilon_{t}\right)\right]
$$


172 Then the conditional variance is obtained from the following equation:

$$
\operatorname{Var}\left(a_{t}\right)=E\left(a_{t}^{2}\right)=E\left[E\left(a_{t}^{2} \mid F_{t-1}\right)\right]=E\left[a_{0}+a_{1} a_{t-1}^{2}\right]=a_{0}+a_{1} E\left(a_{t-1}^{2}\right)
$$

173 Since, according to $E\left(a_{t}=0\right)$ and $\operatorname{Var}\left(a_{t}\right)=E\left(a_{t-1}\right)=E\left(a_{t-1}^{2}\right), a_{t}$ is a static and trend free, we will

174 have:

$$
\begin{aligned}
& \operatorname{Var}\left(a_{t}\right)=a_{0}+a_{1} \operatorname{Var}\left(a_{t}\right) \\
& \operatorname{Var}\left(a_{t}\right)=\frac{a_{0}}{\left(1-\left(a_{0}\right)\right)}
\end{aligned}
$$

$$
E\left[E\left(a_{t}^{4} \mid F_{t-1}\right)\right]=3\left[E\left(a_{t}^{2} \mid F_{t-1}\right)\right]^{2}=3 E\left(a_{0}+a_{1} a_{t-1}^{2}\right)^{2}
$$

180 Therefore:

$$
E\left(a_{t}^{4}\right)=E\left[E\left(a_{t}^{4} \mid F_{t-1}\right)\right]=3 E\left(a_{0}+a_{1} a_{t-1}^{2}\right)^{2}=3 E\left(a_{0}^{2}+2 a_{0} a_{1}^{2} a_{t-1}^{2}+a_{1}^{2} a_{t-1}^{4}\right)
$$

181 If $a_{t}$ is considered as the fourth moment and $m_{4}=E\left(a_{t}^{4}\right)$, then:

$$
m_{4}=3 E\left(a_{0}^{2}+2 a_{0} a_{1} \operatorname{Var}\left(a_{t}\right)+a_{1}^{2} m_{4}\right)=3 a_{0}^{2}\left(1+2 \frac{a_{1}}{1-a_{1}}\right)+3 a_{1}^{2} m_{4}
$$

182 Eventually:

$$
m_{4}=\frac{3 a_{0}^{2}\left(1+a_{1}\right)}{\left(1-a_{1}\right)\left(1-3 a_{1}^{2}\right)}
$$


Although the ARCH model is simple, it often requires a lot of parameters to obtain the proper modeling process. For this reason, we have to look for alternative models (Moffat et al. 2017). Bollerslev (1992) proposed the developed ARCH model as follows:

$$
\begin{aligned}
& a_{t}=\sigma_{t} e_{t} \\
& \sigma_{t}^{2}=\alpha_{0}+\sum_{i=1}^{q} \alpha_{i} \alpha_{t-i}^{2}+\sum_{j=1}^{p} \beta_{j} \sigma_{t-j}^{2}
\end{aligned}
$$
is that marginal distributions are separated from $\mathrm{H}_{\mathrm{X}_{1}, \ldots, \mathrm{X}_{\mathrm{d}}}$ and, therefore, $\mathrm{C}_{U_{1}, \ldots, U_{d}}$ reflects only the

where, $\mathrm{e}_{\mathrm{t}}$ is a random series with zero mean and variance of one. Also, the EGARCH model is a natural logarithmic model of the GARCH model, which was presented by Nelson (1991).

\subsection{Copula functions and Sklar theorem}

Copulas are a flexible way to create joint distributions with different type of margins. Copulas are multivariate distribution functions whose one-dimensional margins are uniform over the range $(0,1)$. A Copula definition is attributed to Sklar (1959) who describes in a theory how univariate distribution functions can be combined in the form of multivariate distributions. Sklar showed that for continuous $d$ dimension random variables $\left\{\mathrm{X}_{1}, \ldots, \mathrm{X}_{\mathrm{d}}\right\}$ with $\mathrm{u}_{\mathrm{j}}=\mathrm{F}_{\mathrm{X}_{\mathrm{j}}}\left(\mathrm{x}_{\mathrm{j}}\right)$ marginal CDFs that $\mathrm{j}=1, \ldots, \mathrm{d}$, there is a d-dimensional copula of $\mathrm{C}_{\mathrm{U}_{1}, \ldots, \mathrm{U}_{\mathrm{d}}}$ such that:

$$
C_{U_{1}, \ldots, U_{D}}\left(U_{1}, \ldots, U_{D}\right)=H_{X_{1}, \ldots, X_{D}}\left(X_{1}, \ldots, X_{D}\right)
$$

where, $\mathrm{u}_{j}$ is $\mathrm{j}^{\text {th }}$ margin and $\mathrm{H}_{\mathrm{X}_{1}, \ldots, \mathrm{X}_{\mathrm{d}}}$ is the joint CDF of $\mathrm{H}_{\mathrm{X}_{1}, \ldots, \mathrm{X}_{\mathrm{d}}}$. Because for continuous random variables, the CDF function of the margins are non-decreasing from 0 to 1 , the $\mathrm{C}_{U_{1}, \ldots, U_{d}}$ copula can be considered as a $\mathrm{H}_{\mathrm{X}_{1}, \ldots, \mathrm{X}_{\mathrm{d}}}$ transformation from $[-\infty, \infty]^{\mathrm{d}}$ to $[0,1]^{\mathrm{d}}$. The result of this transformation relationship between the variables and provide a complete description of the overall dependence 
structure (Nelsen, 2006). The selection of the copula function first depends on determining the degree of dependence of the studied paired variables. In the present study, for estimating the copula dependence parameter, in this study, the method of inference functions for margins (IFM), which is the most common method for estimating the copula parameters, was used (Joe, 1997).

In the case of two variables, it was assumed that the two correlated random variables $X$ and $Y$ were distributed as functions $f_{X}\left(x ; \alpha_{1}, \alpha_{2}, \mathrm{~K}, \alpha_{p}\right)$ and $f_{Y}\left(y ; \lambda_{1}, \lambda_{2}, \mathrm{~K}, \lambda_{r}\right)$, respectively, that $\alpha_{1}, \alpha_{2}, \mathrm{~K}, \alpha_{p}$ are the parameters of $f_{X}(x)$ and $\lambda_{1}, \lambda_{2}, \mathrm{~K}, \lambda_{r}$ are the parameters of $f_{Y}(y)$. The actual number of parameters depends on the type of univariate margin distributions. For $\mathrm{n}$ pairs of 211 independent observations, the likelihood logarithmic functions for $X$ and $Y$, i.e. $212 \ln L_{X}\left(x ; \alpha_{1}, \alpha_{2}, \mathrm{~K}, \alpha_{p}\right)$ and $\ln L_{Y}\left(y ; \lambda_{1}, \lambda_{2}, \mathrm{~K}, \lambda_{r}\right)$, were maximized separately to estimate the 213 parameters. $\hat{\alpha}_{1}, \hat{\alpha}_{2}, \mathrm{~K}, \hat{\alpha}_{p}$ and $\hat{\lambda}_{1}, \hat{\lambda}_{2}, \mathrm{~K}, \hat{\lambda}_{r}$ are the estimated parameters. The log-likelihood 214 function of the joint probability density function of $f_{X, Y}(x, y)$ was considered as follows:

$\operatorname{Ln} L\left(x, y ; \hat{\alpha}_{1}, \hat{\alpha}_{2}, \ldots, \hat{\alpha}_{p}, \hat{\gamma}_{1}, \hat{\gamma}_{2}, \ldots, \hat{\gamma}_{r}, \theta\right)=$

$\operatorname{Ln} L_{C}\left(x, y ; F_{x}(x), F_{y}(y), \theta\right)+\operatorname{Ln} L_{X}\left(x ; \hat{\alpha}_{1}, \hat{\alpha}_{2}, \ldots, \hat{\alpha}_{p}\right)+\operatorname{Ln} L_{Y}\left(y ; \hat{\gamma}_{1}, \hat{\gamma}_{2}, \ldots, \hat{\gamma}_{r}\right)$

to obtain the estimated dependence parameter $\hat{\theta}$. Then, by comparing the results of each copula with the results of the empirical probability, the appropriate copula is selected for the paired

222 variables. Copula-based simulations were also first discussed in the research of Bedford and Cook 223 (2001 and 2002). To obtain the sample $u_{1}, \ldots, u_{d}$ from a d variable copula, the following method is 224 performed: 
$226 \quad w_{j} \stackrel{i, i, d}{:} U[0 ; 1], j=1, \ldots, d$

227 Then;

228

$u_{1}=w_{1}$

$u_{2}:=C_{2 \backslash l}^{-1}\left(w_{2} \mid u_{1}\right)$

M

$u_{d}:=C_{d \mid d-1, \ldots, 1}^{-1}\left(w_{d} \mid u_{d-1}, \ldots, u_{1}\right)$

229 To determine the conditional distribution functions $C_{j \mid j-1, \ldots, l}, j=1, \ldots, d$ required for the pair 230 copulas structure, the recursive relationship for the conditional distribution function with the $h$

231 function is used. For a two-variable copula $C_{i j}\left(u_{i}, u_{i} ; \theta_{i j}\right)$ with parameter $\theta_{\mathrm{ij}}$, the $\mathrm{h}$ functions are

232 defined as follows:

$$
\begin{aligned}
& h_{i \backslash j}\left(u_{i} \mid u_{j} ; \theta_{i j}\right):=\frac{\partial}{\partial u_{j}} C_{i j}\left(u_{i}, u_{j} ; \theta_{i j}\right) \\
& h_{\jmath \backslash i}\left(u_{j} \mid u_{i} ; \theta_{i j}\right):=\frac{\partial}{\partial u_{i}} C_{i j}\left(u_{i}, u_{j} ; \theta_{i j}\right)
\end{aligned}
$$

\subsection{Entropy Theory}

The studied basin in this research is the Dez basin, which has 11 rain gauge stations with a

237 rain gauge station that reflects the general characteristics of the studied basin and its information theory and how stations are selected and ranked. 
In this study, the SVR optimized by the ant colony optimization algorithm was used in two cases. In the first case, it used to investigate the interaction effect of the studied stations in entropy

244 theory and the second case it used to simulate mean monthly discharge (MMD) values affected by 245 monthly rainfall (MR). The first application of this method in water problems was presented by 246 Dibike et al. (2001) for rainfall-runoff modeling (Nazeri-Tahroudi and Ramezani, 2020). SVR is 247 an efficient learning system based on a constrained optimization theory which is used from the 248 principle of induction the minimization of structural error, and leads to a general optimal answer. 249 In the SVM regression model, a function related to the dependent variable $y$, which is a function 250 of several independent variables $\mathrm{x}$, is estimated. Similar to other regression models, it assumes that 251 the relation between independent and dependent variables was determined by an algebraic function 252 such as $\mathrm{f}(\mathrm{x})$ plus some amount of confusion (allowed error $\varepsilon$ ):

$$
\begin{aligned}
& f(x)=W^{T} . \phi(x)+b \\
& y=f(x)+\text { noise }
\end{aligned}
$$

253 If $\mathrm{W}$ (vector of coefficients) and $\mathrm{b}$ (constant) are the properties of the regression function and $254 \phi$ is also the kernel function, then the object is finding the functional form for $\mathrm{f}(\mathrm{x})$. This topic is 255 achieved by training the SVM model through a set of samples (training set). Therefore, to calculate $256 \mathrm{~W}$ and $\mathrm{b}$, it is necessary to optimize the error function in the $\varepsilon-S V M$ model by considering the 257 conditions listed in Equation 22.

$$
\frac{1}{2} W^{T} W+C \sum_{i=1}^{N} \xi_{i}+C \sum_{i=1}^{N} \xi_{i}^{*}
$$




$$
\begin{aligned}
& W^{T} . \phi\left(x_{i}\right)+b-y_{i} \leq \varepsilon+\xi_{i}^{*} \\
& y_{i}-W^{T} . \phi\left(x_{i}\right)-b \leq \varepsilon+\xi_{i} \\
& \xi_{i}, \xi_{i}^{*} \geq 0 \quad, \quad i=1, \ldots, N
\end{aligned}
$$

where, $\mathrm{C}$ is a positive integer that determines the penalty when the model training error occurs.

$259 \phi$ is the kernel function, $\mathrm{N}$ is the number of samples, and the two indices of $\xi_{i}$ and $\xi_{i}^{*}$ are the

260 Slack variables, which determine the upper and lower limit of the training error associated with

261 the allowed error value $\varepsilon$. In problems, it is predicted that the data is within the boundary range $\varepsilon$.

262 Now, if the data is out of range $\varepsilon$, then there will be an error equal to $\xi_{i}$ and $\xi_{i}^{*}$. It is worth

263 mentioning that the SVM model solves the problems caused by the under fitting and over fitting

264 by simultaneously minimizing two terms $W^{T} . W / 2$ and training errors, namely $C \sum_{i=1}^{N}\left(\xi_{i}+\xi_{i}{ }_{i}^{*}\right)$,

265 in Equation 23. Therefore, by introducing 2 Lagrange coefficients $a_{i}$ and $a_{i}^{*}$, the optimization

266 problem will be solved with the numerical maximization of the following quadratic function:

267

$$
\begin{aligned}
& \sum_{i=1}^{N} y_{i}\left(a_{i}+a_{i}^{*}\right)-\varepsilon \sum_{i=1}^{N}\left(a_{i}+a_{i}^{*}\right)- \\
& 0.5 \sum_{i, j=1}^{N}\left(a_{i}+a_{i}^{*}\right)\left(a_{j}+a_{j}^{*}\right) \phi\left(x_{i}\right)^{T} \phi\left(x_{j}\right) \\
& \sum_{i=1}^{N}\left(a_{i}+a_{i}^{*}\right)=0 \\
& 0 \leq a_{i} \leq C, \quad 0 \leq a_{i}^{*} \leq C, \quad i=1,2, \ldots, N
\end{aligned}
$$

269 The above objective function in Equation 25 is a convex function and therefore, the solution of 270 Equation 25 would be unique and optimal. After defining the Lagrange coefficients in Equation 
27125 , the characteristics $w$ and $b$ in the SVM regression model is calculated using the Karush-Kan-

272 Tucker theory, where $W=\sum_{j=1}^{N}\left(a_{i}+a_{i}^{*}\right) \phi\left(x_{i}\right)$. As a result, for the SVM regression model there is:

$$
W=\sum_{i=1}^{N}\left(a_{i}+a_{i}^{*}\right) \phi\left(x_{i}\right)^{T} \phi(\mathrm{x})+b
$$

273 It should be noted that the Lagrange terms $\left(\left(a_{i}+a_{i}^{*}\right)\right)$ can be zero or non-zero. Therefore,

274 only data sets whose coefficients $\overline{a_{i}}$ are non-zero are entered in the final regression equation and

275 this data set is known as the support vectors. In simple terms, support vectors are data that help to

276 create a regression function. Among the vectors mentioned, those whose $\left|\overline{a_{i}}\right|$ values are less than

$277 \mathrm{C}$ are called margin support vectors. When the value $\left|\overline{a_{i}}\right|$ of the support vectors is equal to $\mathrm{C}$, it is

278 known as an error support vector or a bounded support vector. Margin support vectors are found

279 on the margin of the insensitive boundary while error support vectors are out of range. Finally, the

280 regression SVM function can be rewritten in the following form:

$$
f(x)=\sum_{i=1}^{N} a_{i} \phi\left(x_{i}\right)^{T} \phi\left(x_{j}\right)+b
$$

In Equation 26, the calculation of $\phi(x)$ in its characteristic space may be very complicated. To

282 solve this problem, the regular approach in the SVM regression model is the selection of a kernel

283 function as $K\left(x_{i}, x\right)=\phi\left(x_{i}\right)^{T} \phi \sqrt{b^{2}-4 a c}$. Various kernel functions can be used to construct

284 different types of $\varepsilon$-SVM models. The most commonly used kernel functions available in the 285 vector regression model are: A polynomial kernel with 3 target characteristics, a sigmoid kernel 286 containing 2 target characteristics and kernel of radial base functions (RBF) with a target 287 characteristic. 


\subsection{Ant colony optimization algorithm (ACO)}

The ant colony optimization (ACO) algorithm was first proposed by Colorni et al. (1991).

291 One of the first applications of the ACO algorithm has been to solve the traveling salesman 292 problem. Since the ACO algorithms depend on the type of use and similarity of the ants moving 293 on the graph, the use of the traveling salesman problem to explain the basic principles of ant 294 algorithms was highly logical, and it was originally a typical example for introducing this 295 algorithm. For more information, see (Colorni et al. 1991, Dorigo, 1992; Nazeri-Tahroudi and 296 Ramezani, 2020).

\section{Results and Discussion}

There are 11 rain gauge stations in the Dez basin with recorded data in the period of 1988-

2018. In this study, entropy theory was used to select the best and most valuable rain gauge station that clearly shows the characteristics of the studied basin. By applying the entropy theory and calculating its indicators, the studied stations were ranked. The results of ranking and information transfer index (ITI) of the studied stations are presented in Table 2. The results of the study and ranking of the studied stations based on the N(i) index of entropy theory showed that Vanaei station

305 is the best and most valuable rain gauge station in the region that the rainfall values of this station can be generalized to the whole basin area. It should be noted that the support vector regression method optimized with the ant colony optimization (ACO) algorithm was used to evaluate the interaction of rain gauge stations (Tahroudi et al. 2019c). The results showed that the information transfer of Vanaei station is established with other stations and is related to all existing stations. By selecting Vanaei station as the representative station, the correlation between the MMD values

311 of the Talezang hydrometric station and the MR values of Vanaei station was investigated. 
The results of evaluating the Information Transfer Index (ITI) also showed that, except of the two stations Kamandan and Sepidasht Sezar, other studied rain gauge stations are located in the 317 surplus area in the basin in terms of concentration of stations. In this study, in order to simulate the MMD values given by the occurrence of MR values, the performance of ARCH-based models 319 (Copula-GARCH models) and the OSVR-based model was investigated and compared. First, the correlation between the mentioned paired variables was investigated. The scatter diagram of the

321 studied data at the real scale is presented in Figure 2. In this figure, the empirical contour lines, 322 histograms of the studied data and Kendall's tau coefficient are presented. The value of the 323 Kendall's tau statistic that reflect the correlation between the studied variables is 0.34 which is 324 acceptable for further analysis.

\section{Fig. 2.} values of Vanaei rain gauge station using Copula-GARCH model

Next step, in order to present the Copula-GARCH model, it is first necessary to fit time series models on the studied data. In this regard, VAR model was used (Shahidi et al. 2020). The data were analyzed using the VAR model with different delays and finally the residual series of the 331 VAR model was extracted for the paired variables. The basis of modeling based on the Copula332 GARCH model is the VAR model. This model actually models the average part of the time series 333 and due to the existence of heteroskedasticity in the time series of rainfall and flow discharge, 334 modeling the variance of data was also investigated. In this regard, the residual series was extracted 
335 for the paired variables and fitted by the GARCH model. The residual series were produced from 336 the GARCH model. Prior to fitting the GARCH model, the structural stability of the residual series 337 was investigated using the Ordinary least squares (OLS) residuals and Cusum tests and presented 338 in Figure 3 (Ploberger and Krämer, 1992).

\section{Fig. 3.}

The Cusum test calculates the process of empirical fluctuations using a specific method from 341 a generalized statistical framework. According to Figure 3 and the confidence intervals, the results 342 of this test were also confirmed (Kramer et al. 1991). As can be seen, the OLS-based CUSUM 343 process has not exceeded the confidence intervals. Hence, there is no evidence of structural change. 344 In the next step, for joint frequency analysis of the paired residual series of the VAR model, the 345 fitness of different copula functions and their rotational form were examined. Akaike information 346 criterion (AIC), Bayesian information criterion (BIC) and Log-Likelihood (Log-Like) were used 347 to select the superior copula function. The results of goodness of fit tests were performed for the 348 paired residual series confirmed the superiority of Gaussian copula to other copulas. Accordingly, 349 the Gaussian copula function was selected with AIC, BIC and Log-Like values of $-90.9,-87$ and 35046.4 , respectively, with a copula parameter of 0.51 . After selecting the Gaussian copula as the 351 superior copula, the simulation based on the bivariate copula of the paired residual series was 352 investigated. The results of simulation of the mean monthly discharge (MMD) of Talezang station 353 given recorded monthly rainfall (MR) at the Vanaei rain gauge station using Copula-GARCH 354 model in the period of 1988-2018 were presented as Figures 4 and 5. 
According to Figure 4, it can be seen that the simulated MMD $\left(\mathrm{m}^{3} / \mathrm{s}\right)$ data has a good agreement with the observed data in both training and test stages. The maximum and minimum points are well simulated in most cases. In some cases, overestimation is seen, but on average, there is a good correlation between the observed and simulated values based on the CopulaGARCH model. The calibration results of the Copula-GARCH model are also shown in Figure 5, except for two overestimated cases, all the simulated data are in the $99 \%$ confidence intervals and the accuracy of the model is also confirmed. The simulation based on Copula-GARCH has the RMSE of $79.64 \mathrm{~m}^{3} / \mathrm{s}$ on a monthly scale. According to the correlation values and Nash-Sutcliffe statistics, this RMSE is acceptable and the performance of the model in the simulation of MMD values $\left(\mathrm{m}^{3} / \mathrm{s}\right)$ given the occurrence of MR values is confirmed. The results presented in Figures 4 and 5 are based on modeling the mean and variance of the MMD series and also include considering its heteroskedasticity, which is also modeled by the copula-based model. According

to the statistics presented in Figure 5, it can be concluded that the proposed hybrid model has a 371 high ability to simulate MMD values given by MR values. was performed by considering the MR values at the Vanaei rainfall station as input. The parameters of the OSVR model (Epsilon, c and Sigma) were optimized using the ant colony optimization

378 (ACO) algorithm to achieve higher accuracy, and with 100 iterations, the values of Epsilon, c and 379 Sigma were estimated 21.473, 1000 and 12.91, respectively. The results showed that in iteration 38013 , the OSVR model reached the optimal state and the cost function obtained the lowest value. 381 The results of the objective function (RMSE) are shown in Figure 6. As can be seen from Figure 
3826 , the OSVR model was able to reduce the simulation RMSE of MMD values from about $200 \mathrm{~m}^{3} / \mathrm{s}$

383 to $105.8 \mathrm{~m}^{3} / \mathrm{s}$ during iterations. There was no improvement in the results from 13 to 100 repetitions.

384 Finally, using the optimized coefficients of the OSVR model, the simulation of the MMD values

385 was performed given MR values and the simulation results are presented in Figures 7 and 8.

386

387

388

389

390

391

392

393

394

395

396

397

398

399

400

401

402

403

404

405

\section{Fig 6.}

Fig 7.

As it can be seen from Figure 7, there is good agreement between observed MMD values and corresponding values simulated by the OSVR model. The minimum points in these simulations are not well estimated due to the presence of zero MR data. Also, in some months, the maximum values are not well simulated. According to Figure 8, the results of the study and the RMSE of the OSVR model in simulating MMD values showed that the RMSE of the model is about $106\left(\mathrm{~m}^{3} / \mathrm{s}\right)$ and the NSE of the model is $78 \%$. According to the $99 \%$ confidence intervals, the results showed that about 15 points of the simulated MMD values $\left(\mathrm{m}^{3} / \mathrm{s}\right)$ are outside the confidence range, which indicates overestimation or underestimation of the target points. However, the performance of the model is acceptable according to the presented results.

\section{Fig 8.}

By using and implementing the Copula-GARCH model, which actually consists of the VAR, VAR-GARCH models and the joint residual series of the VAR-GARCH model, the NSE of this model compared to the OSVR model was improved by about $15 \%$. On the other hand, compared to the OSVR model, the $\mathrm{R}^{2}$ and RMSE statistics of the simulations by the Copula-GARCH model have been improved by $11 \%$ and $36 \%$, respectively. The accuracy of simulation results of MMD values $\left(\mathrm{m}^{3} / \mathrm{s}\right)$ improved about $36 \%$, which indicates a decrease of RMSE by $26.16\left(\mathrm{~m}^{3} / \mathrm{s}\right)$. Finally, Violin Plot and Taylor Diagram were used to compare the performance of the used models and also to evaluate their certainty in simulating the MMD values of the Talezang hydrometric station. 
The Violin plot of observed and simulated data is presented in Figure 10 and Taylor diagram of Copula-GARCH and OSVR models also presented in Figure 11.

\section{Fig. 9.}

Fig. 10.

As can be seen from Figures 9 and 10, the results of the studied models in the MMD simulation of the Talezang hydrometric station are very close to each other based on the evaluation criteria. In other words, evaluation criteria cannot provide any information on how data are distributed. Therefore, using plots such as Violin and Taylor diagrams can be very useful. The violin plot is another form of box plot. Box plots show only the minimum, maximum, mean, and quarters of the data, but the violin plot is used to visualize the data distribution and its probability density. According to the presented violin plot, it can be seen that the simulated time series with the OSVR model has slightly overestimating and the maximum values are simulated more than the corresponding observed values. But in general, the Copula-GARCH model simulates MMD values better than the OSVR model. According to Figure 9, the range of variation of MMD values, as well as the range of 5 and $95 \%$ of the values simulated by the Copula-GARCH model, is closer to the observed values, which increases the reliability of the model. As it can be seen from Figure 9, the Copula-GARCH model better covers the range of data changes. Appropriate certainty in copula-based simulation of the different meteorological and hydrological values has been investigated and confirmed in various studies. Recent studies in simulation of different hydrometeorological variables using two and multidimensional copula functions show that these functions have high ability and accuracy in bivariate simulations of meteorological and hydrological phenomena (Bezak et al. 2017; Ahmadi et al. 2018; Nazeri Tahroudi at al. 2020 a \& b; Kim et al. 2019). Regarding the simulation of other variables using copula functions, Bazak et 
429 al. (2017) also stated that the copula functions have acceptable accuracy in the simulation of 430 sediment values and have a higher accuracy compared to the regression method. In addition, the 431 results of this study showed that by using the copulas, the accuracy and efficiency of the hybrid 432 VAR-GARCH model can be improved, that are consistent with the results of Yoo et al. (2016). 433 Yuan et al. (2020) also confirmed the acceptable accuracy of the Copula-GARCH model in 434 agricultural commodity price modeling by combining copulas with GARCH models. The Taylor 435 diagram (Figure 10) is based on the geometric relationship among the correlation coefficient (R), 436 the time series standard deviation, and the root mean square difference. This diagram is a good 437 tool for evaluating various methods. The reference point (hollow circle between standard deviation 438200 and 300) indicates the position of the observed values based on the standard deviation of the 439 time series. The position of the simulated data with OSVR and Copula-GARCH models is plotted 440 based on the root mean square difference, its correlation coefficient with the observed values and 441 the time series standard deviation in Figure 10. Due to the fact that the Copula-GARCH location 442 is closer to the reference point, it can be concluded that the Copula-GARCH model have a higher 443 accuracy than the OSVR model in simulating the MMD values.

\section{Conclusion}

In this study, a Copula-GARCH model and a VAR model were used to simulate MMD values of the Talezang hydrometric station given MR values of Vanaei rain gauge in the Dez basin in

448 southwestern Iran. Due to the influence of MR time series on MMD values on a monthly scale, 449 vector autoregressive model (VAR) was used as the base model. The VAR model provides 450 relatively good results due to the involvement of an effective parameter in the modeling. The 451 correlation of the studied variables using Kendall's tau test was 0.34, which satisfies the initial 
452 condition of using copula-based models. The results of the joint frequency analysis of the paired

453 variables showed that the Gaussian copula has the best fitness on the residual series of VAR model.

454 The results of simulation of MMD values based on Copula-GARCH model showed that this model

455 has a high ability to simulate the studied variables and has high accuracy. Appropriate estimation

456 of MMD values is observed in all months and in the whole range of changes in MMD values. The

457 maximum and minimum points of the MMD values are also well estimated throughout the studied

458 period. In this study, in addition to the copula model, the OSVR model was applied to simulate

459 monthly runoff. After estimating the coefficients of the SVR model using the ant colony

460 optimization algorithm, the MMD values were simulated according to the MR values. The results

461 showed that the OSVR model did not simulate the minimum points or base flow well due to the

462 presence of zero data in the rainfall time series. The values of $\mathrm{R}^{2}, \mathrm{RMSE}$ and NSE statistics also

463 confirmed the superiority of the Copula-GARCH model over the OSVR model. In addition to the

464 mentioned statistics, the results of Violin plot and Taylor diagram also showed higher certainty of

465 Copula-GARCH model than OSVR model. The proposed approach, due to the use of the copula

466 function and the appropriate marginal distribution functions for each series, brought the simulation

467 results closer to the observed values, which increased the model accuracy. Using this approach

468 will improve performance in simulation of important meteorological and hydrological variables,

469 which will be very useful in water resources planning and management.

470

\section{Acknowledgements}

472

The authors would like to thank Politecnico di Milano for providing the facilities to the first

473 author as a visiting researcher. Also, the authors would like to thank Iran Water Resources

474 Management Company for providing the data. 


\section{Authors' Contributions Conceptualization:}

Methodology: M. Nazeri Tahroudi and F. Ahmadi; Formal analysis and investigation: M. Nazeri Tahroudi, R. Mirabbasi, Y. Ramezani and F. Ahmadi; Writing-original draft preparation: M. Nazeri Tahroudi; Writing_review and editing: M. Nazeri Tahroudi, R. Mirabbasi, Y. Ramezani and F. Ahmadi; Supervision: R. Mirabbasi, Y. Ramezani.

\section{Declarations}

Funding (Not applicable)

Conflicts of interest/Competing interests (The authors declare no conflicts of interest) Availability of data and material (The data and material used in this work are available from the corresponding author by request)

Ethical Approval (Not applicable)

Consent to participate (Not applicable)

Consent to Publish (Not applicable)

Consent for Publication (Not applicable)

\section{References}

Abdi A, Hassanzadeh Y, Talatahari S, Fakheri-Fard A, Mirabbasi R (2017a) Regional bivariate modeling of droughts using L-comoments and copulas. Stochastic Environmental Research and Risk Assessment 31(5):1199-1210.

Ahmadi F, Radmanesh F, Sharifi M R, Mirabbasi R (2018) Bivariate frequency analysis of low flow using Ccopula functions (Case study: Dez River Basin, Iran). Environmental Earth Sciences 77: 643 DOI: 10.1007/s12665-018-7819-2. 
Ayantobo O O, Li Y, Song S, Javed T, Yao N (2018) Probabilistic modelling of drought events in China via 2-dimensional joint copula. Journal of Hydrology 559: 373-391.

Bedford T, Cooke R M (2001) Probability density decomposition for conditionally dependent random variables modeled by vines. Annals of Mathematics and Artificial intelligence 32(4): 245-268.

Bedford T, Cooke R M (2002) Vines: A new graphical model for dependent random variables. Annals of Statistics 30(4): 1031-1068.

Bollerslev T, Chou R Y, Kroner K F (1992) ARCH modeling in finance. A selective review of the theory and empirical evidence. Journal of Econometrics 52: 5-59.

Colorni A, Dorigo M, Maniezzo V (1991) Ant system: An autocatalytic optimizing process. Dipartimento Di Elet-tronica, Politecnico Di Milano, Milan, Italy.

Dibike Y B, Velickov S, Solomatine D, Abbott M B (2001) Model induction with support vector machines: introduction and applications. Journal of Computing in Civil Engineering 15(3): 208-216.

Dorigo M (1992) Optimization, learning and natural algorithms. PhD Thesis, Politecnico di Milano

Duan J C (1996) A unified theory of option pricing under stochastic volatility-from GARCH to diffusion. Hong Kong University of Science and Technology, Research project

Engle R F (1982) Autoregressive conditional heteroscedasticity with estimates of the variance of United Kingdom inflation. Econometrica 50(4): 987-1007.

Floros C, Jaffry S, Lima G V (2007) Long memory in the Portuguese stock market. Studies in Economics and Finance 24(3): 220-232. 
Guo, A, Wang, Y (2017). Assessment of variability in the hydrological cycle of the Loess Plateau, China: examining dependence structures of hydrological processes. AGUFM, 2017, GC41C-1028.

Hollander M, Wolfe D A, Chicken E (2014) Nonparametric statistical methods. New York: Wiley.

Khozeymehnezhad H, Nazeri-Tahroudi M (2020) Analyzing the frequency of non-stationary hydrological series based on a modified reservoir index. Arabian Journal of Geosciences 13(5): 1-13.

Khozeymehnezhad H, Tahroudi M N (2019) Annual and seasonal distribution pattern of rainfall in Iran and neighboring regions. Arabian Journal of Geosciences 12(8): 1-11.

Kim J E, Yoo J, Chung G H, Kim T W (2019) Hydrologic risk assessment of future extreme drought in South Korea using bivariate frequency analysis, Water 11(10): 2052.

Krämer W, Ploberger W, Schlüter I (1991) Recursive vs. OLS residuals in the CUSUM test. In Economic Structural Change (pp. 35-47). Springer, Berlin, Heidelberg.

Li F, Zheng Q (2016) Probabilistic modelling of flood events using the entropy copula. Advances in Water Resources, 97: 233-240.

Modarres R, Ouarda T B (2013) Generalized autoregressive conditional heteroscedasticity modelling of hydrologic time series. Hydrological Processes 27(22): 3174-3191.

Moffat I U, Akpan E A, Abasiekwere U A (2017) A time series evaluation of the asymmetric nature of heteroscedasticity: An EGARCH approach. International Journal of Statistics and Applied Mathematics 2(6): 111-117.

Nazeri-Tahroudi M, Ramezani, Y (2020) Estimation of Dew Point Temperature in Different Climates of Iran Using Support Vector Regression. Idojaras 124(4): 521-539.

Nelsen R B (2006) An introduction to copulas. Springer, New York, 269p. 
541 Nelson D B (1991) Conditional heteroskedasticity in asset returns: A new approach.

$542 \quad$ Econometrica 59(2): 347-370.

543 Ploberger W, Krämer W (1992) The CUSUM test with OLS residuals. Econometrica 60(2):

$544 \quad 271-285$

545 Ramezani Y, Tahroudi M N (2020) Improving the performance of the SPEI using four-parameter 546 distribution function. Theoretical and Applied Climatology 139(3): 1151-1162.

547 Ramezani Y, Tahroudi M N, Ahmadi F (2019) Analyzing the droughts in Iran and its eastern neighboring countries using copula functions. IDOJARAS 123(4): 435-453.

549 Salvadori G, De Michele C, Kottegoda N T, Rosso R (2007) Extremes in nature: an approach using 550 copulas (Vol. 56). Springer Science \& Business Media.

551 Serinaldi F, Bonaccorso B, Cancelliere A, Grimaldi S (2009) Probabilistic characterization of 552 drought properties through copulas. Physics and Chemistry of the Earth, Parts A/B/C 34(1012): 596-605.

554 Shahihi A, Ramezani Y, Nazeri-Tahroudi N, Mohammadi S (2020) Application of vector autoregressive models to estimate pan evaporation values at the Salt Lake Basin, Iran. Idojaras 124(4): 463-482, DOI:10.28974/idojaras.2020.4.3.

557 Sims C A (1980) Macroeconomics and reality. Econometrica 48(1): 1-48.

558 Sklar A (1959) Fonctions de Repartition and Dimensions et LeursMarges. Publications de 559 L'Institute de Statistique, Universite' de Paris, Paris 8: 229-231.

560 Tahroudi M N, Khalili K, Ahmadi F, Mirabbasi R, Jhajharia D (2019a) Development and 561 application of a new index for analyzing temperature concentration for Iran's climate. International Journal of Environmental Science and Technology 16(6): 2693-2706. 
563 Tahroudi M N, Pourreza-Bilondi M, Ramezani Y (2019b) Toward coupling hydrological and

564

565

566

567

568

569

570

571

572

573

574

575

576

577

578

579

580

581

582

583 meteorological drought characteristics in Lake Urmia Basin, Iran. Theoretical and Applied Climatology 138(3-4): 1511-1523.

Tahroudi M N, Ramezani Y De Michele C, Mirabbasi R (2020a) A new method for joint frequency analysis of modified precipitation anomaly percentage and streamflow drought index based on the conditional density of copula functions. Water Resources Management 34(13): 42174231.

Tahroudi M N, Ramezani Y, De Michele C, Mirabbasi R (2020b) Analyzing the conditional behavior of rainfall deficiency and groundwater level deficiency signatures by using copula functions. Hydrology Research 51(6): 1332-1348.

Tahroudi M N, Siuki A K, Ramezani Y (2019c) Redesigning and monitoring groundwater quality and quantity networks by using the entropy theory. Environmental Monitoring and Assessment 191(4): 250.

Tse Y K, Tsui A K. C (2002) A multivariate generalized autoregressive conditional heteroscedasticity model with time-varying correlations. Journal of Business Economic Statistics 20(3): 351-362.

Wang W, Van Gelder P H A J M, Vrijling J K, Ma J (2005) Testing and modelling autoregressive conditional heteroskedasticity of streamflow processes. Nonlinear Processes in Geophysics, European Geosciences Union (EGU) 12(1): 55-66. hal-00302471

Watanabe T (2012) Quantile forecasts of financial returns using realized GARCH models. The Japanese Economic Review 63(1): 68-80. 
584 Yoo J, Kim D, Kim H, Kim, T W (2016) Application of copula functions to construct confidence 585 intervals of bivariate drought frequency curve. Journal of Hydro-environment Research 11: $113-122$.

587 Yuan X, Tang J, Wong W K, Sriboonchitta S (2020) Modeling co-movement among different 588 agricultural commodity Markets: a Copula-GARCH Approach. Sustainability 12(1): 393.

589 Yusof F, Kane I L (2013) Volatility modeling of rainfall time series. Theoretical and Applied 590 Climatology 113(1-2): 247-258. 

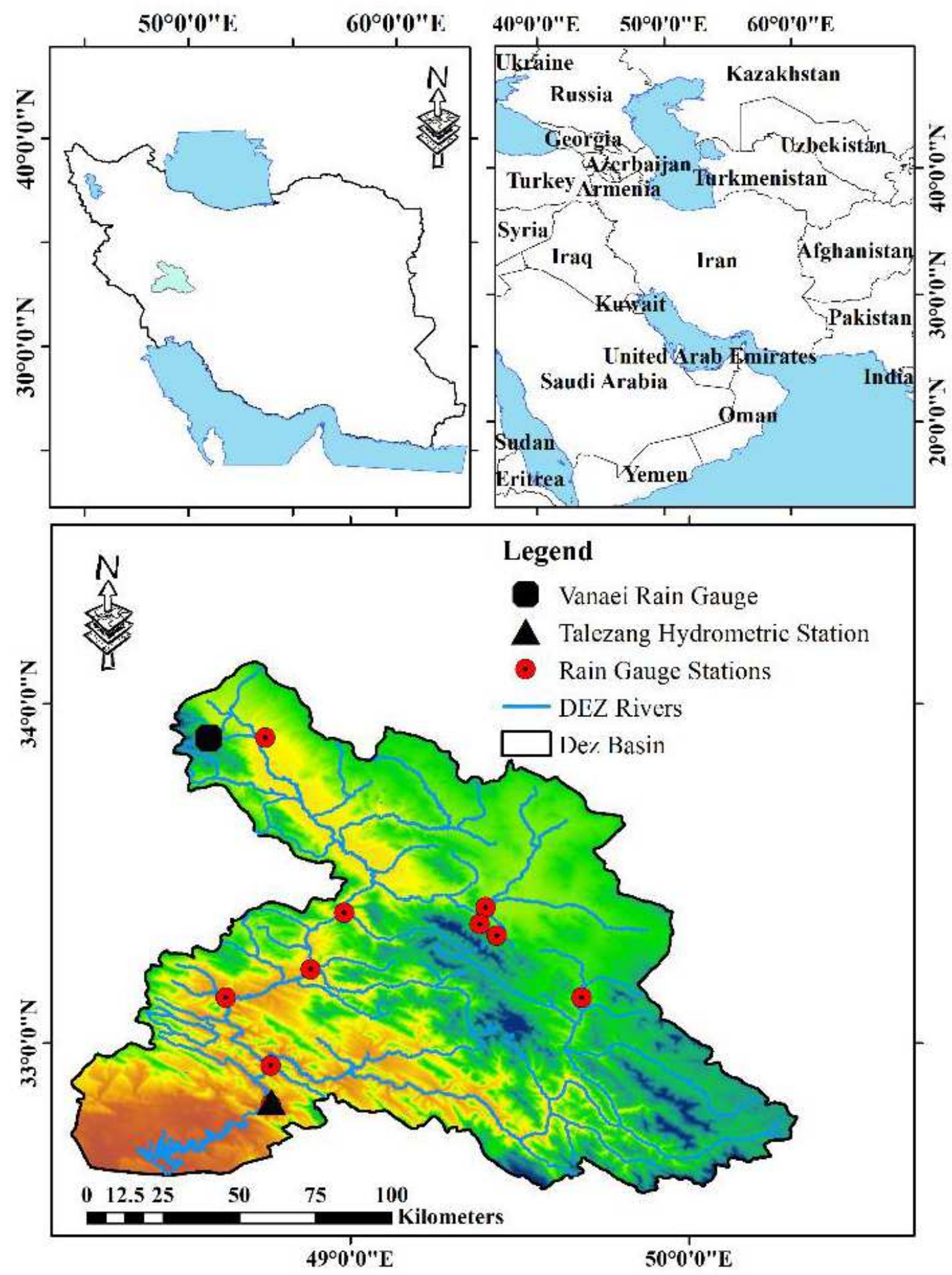

Figure 1

Location map of the studied rain gauge and hydrometric stations in Dez basin Note: The designations employed and the presentation of the material on this map do not imply the expression of any opinion whatsoever on the part of Research Square concerning the legal status of any country, territory, city or 
area or of its authorities, or concerning the delimitation of its frontiers or boundaries. This map has been provided by the authors.
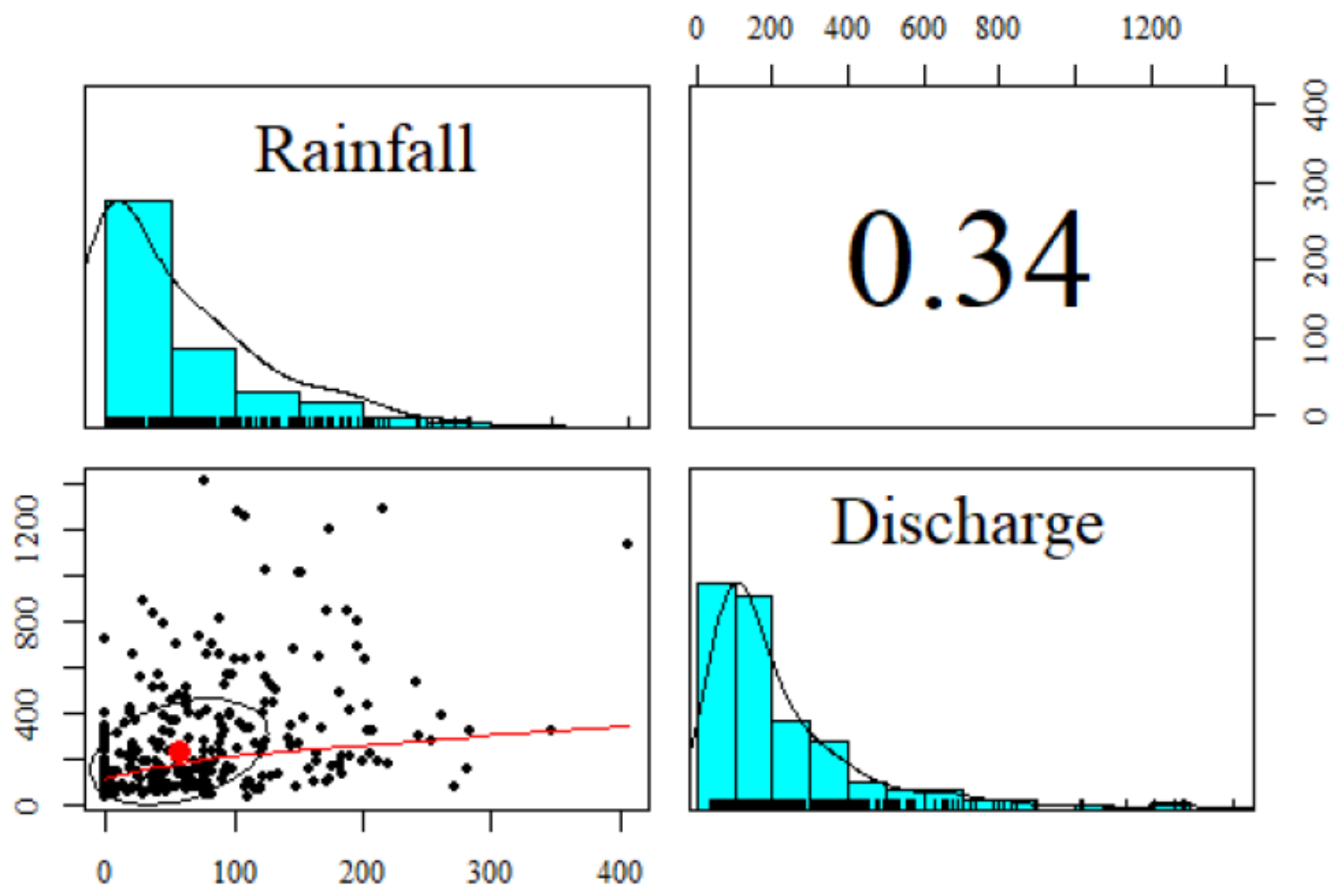

Figure 2

Kendall's tau, histogram and empirical contour lines of rainfall $(\mathrm{mm})$ and flow discharge $(\mathrm{m} 3 / \mathrm{s})$ series

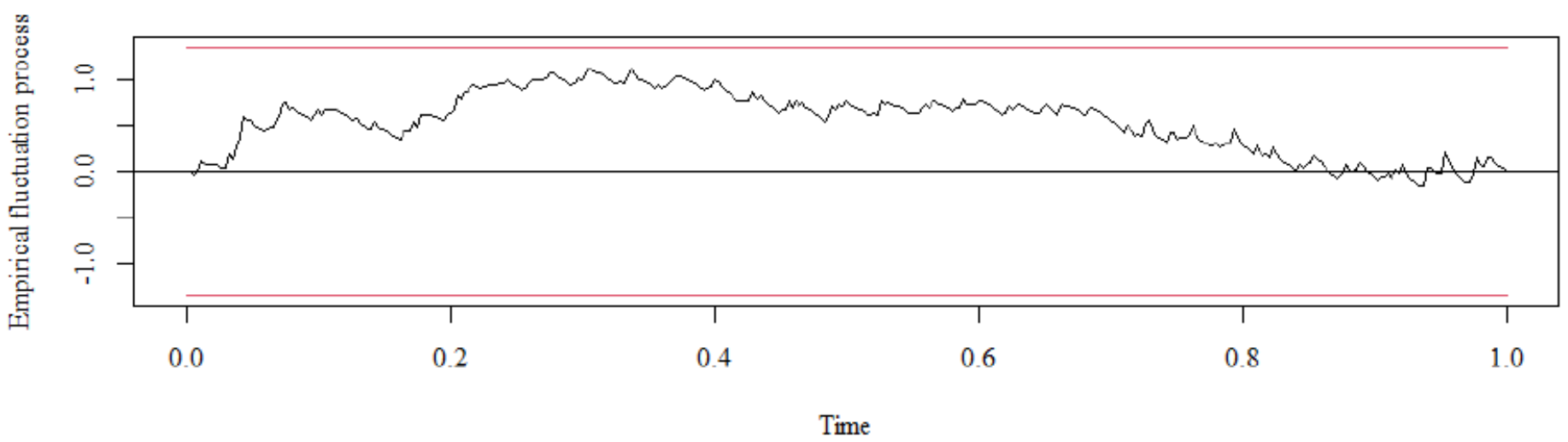

\section{Figure 3}

The OLS-based Cusum process of VAR(p) model (the red lines show the confidence intervals) 


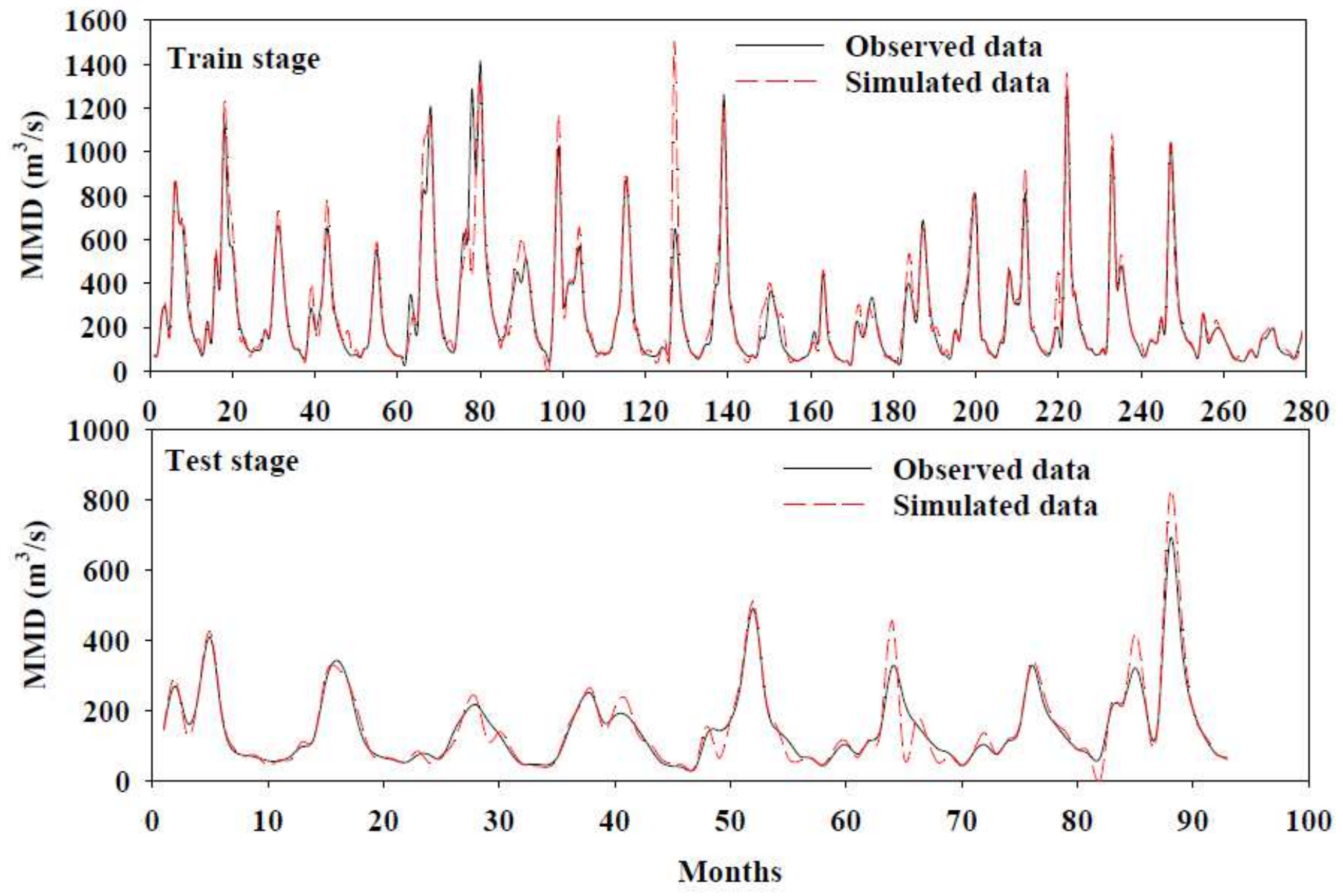

Figure 4

Results of simulation the MMD (m3 / s) of Talezang hydrometric station given MR values $(\mathrm{mm})$ of Vanaei rain gauge station using Copula-GARCH model in two training and test stages (1988-2018) 


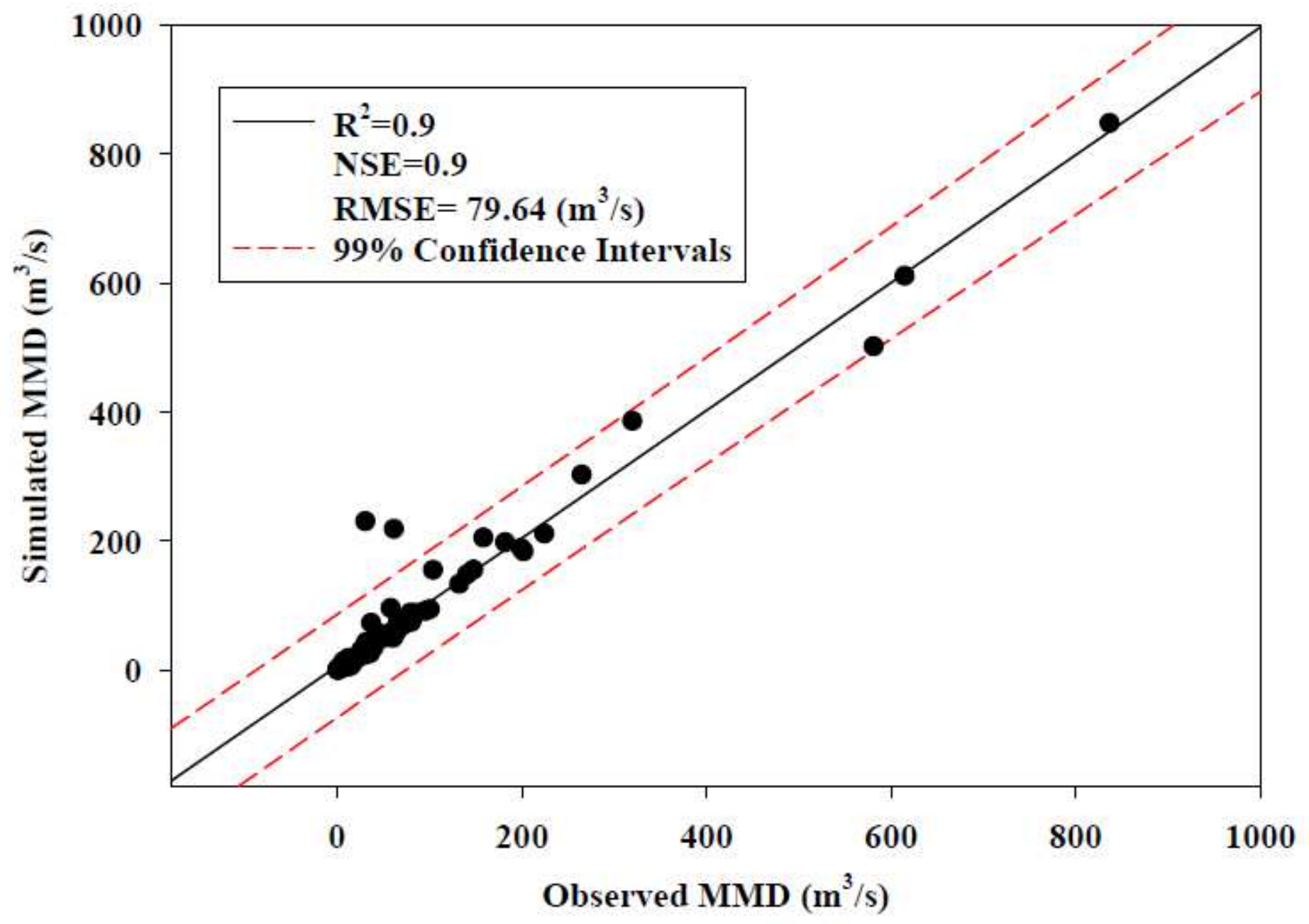

Figure 5

The simulated values of the MMD (m3/s) using Copula-GARCH model versus observed values at the Talezang hydrometric station 


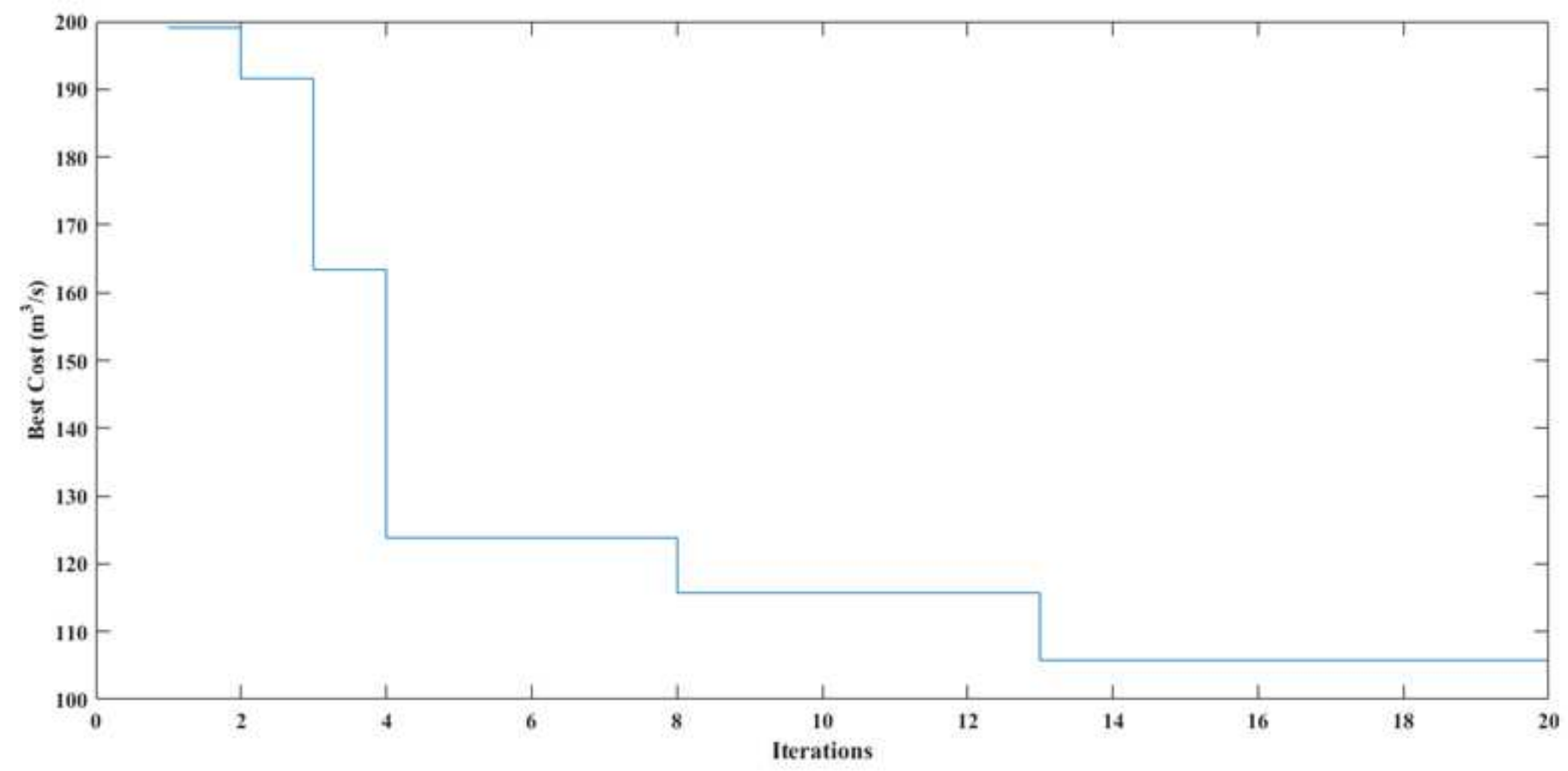

Figure 6

Results of objective function (RMSE) improvement in different iterations to optimize OSVR model coefficients 


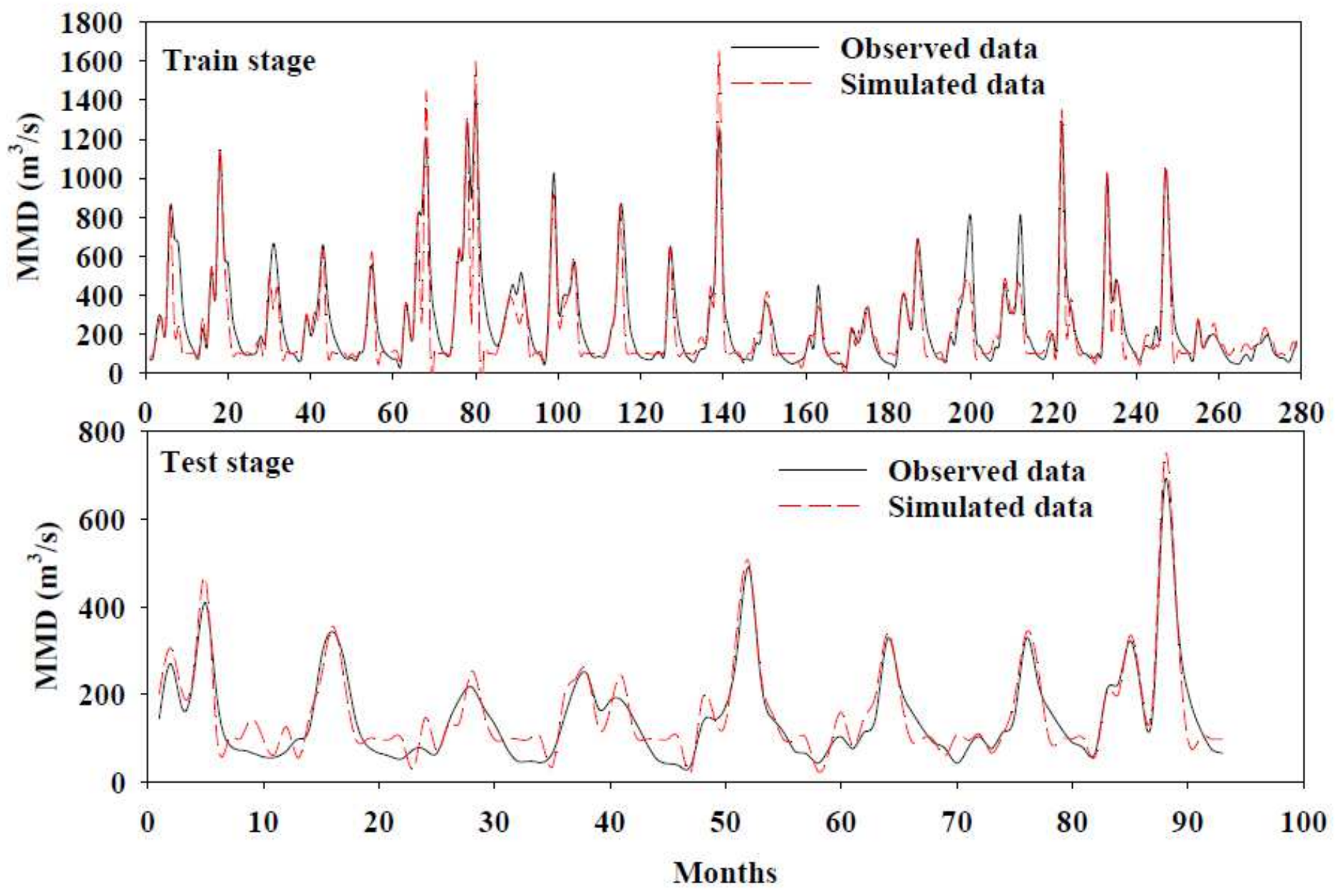

Figure 7

Results of simulation the MMD (m3 / s) of Talezang hydrometric station given MR values $(\mathrm{mm})$ of Vanaei rain gauge station using OSVR model in two training and test stages (1988-2018) 


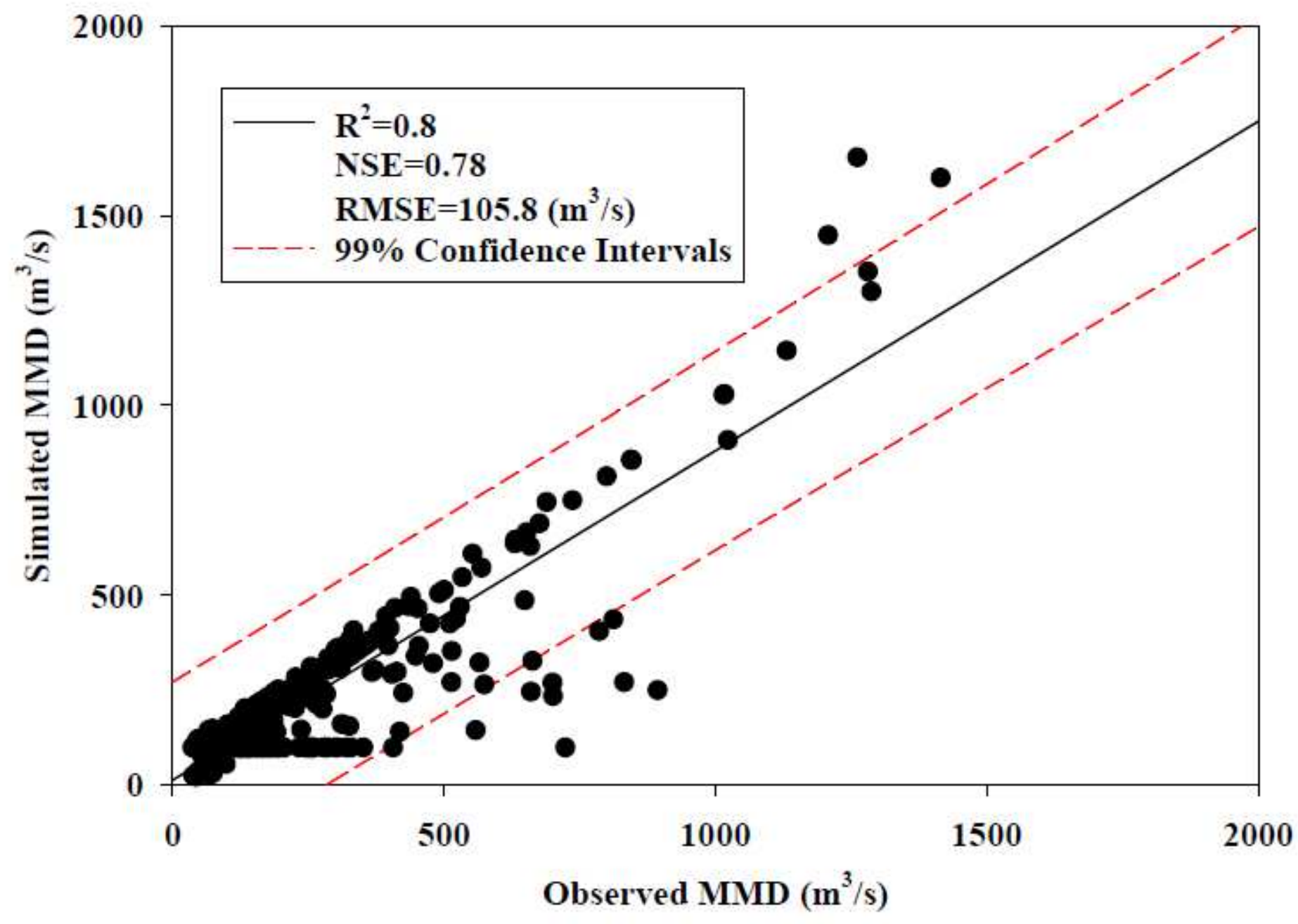

Figure 8

The simulated values of the MMD (m3/s) using OSVR model versus observed values at the Talezang hydrometric station 


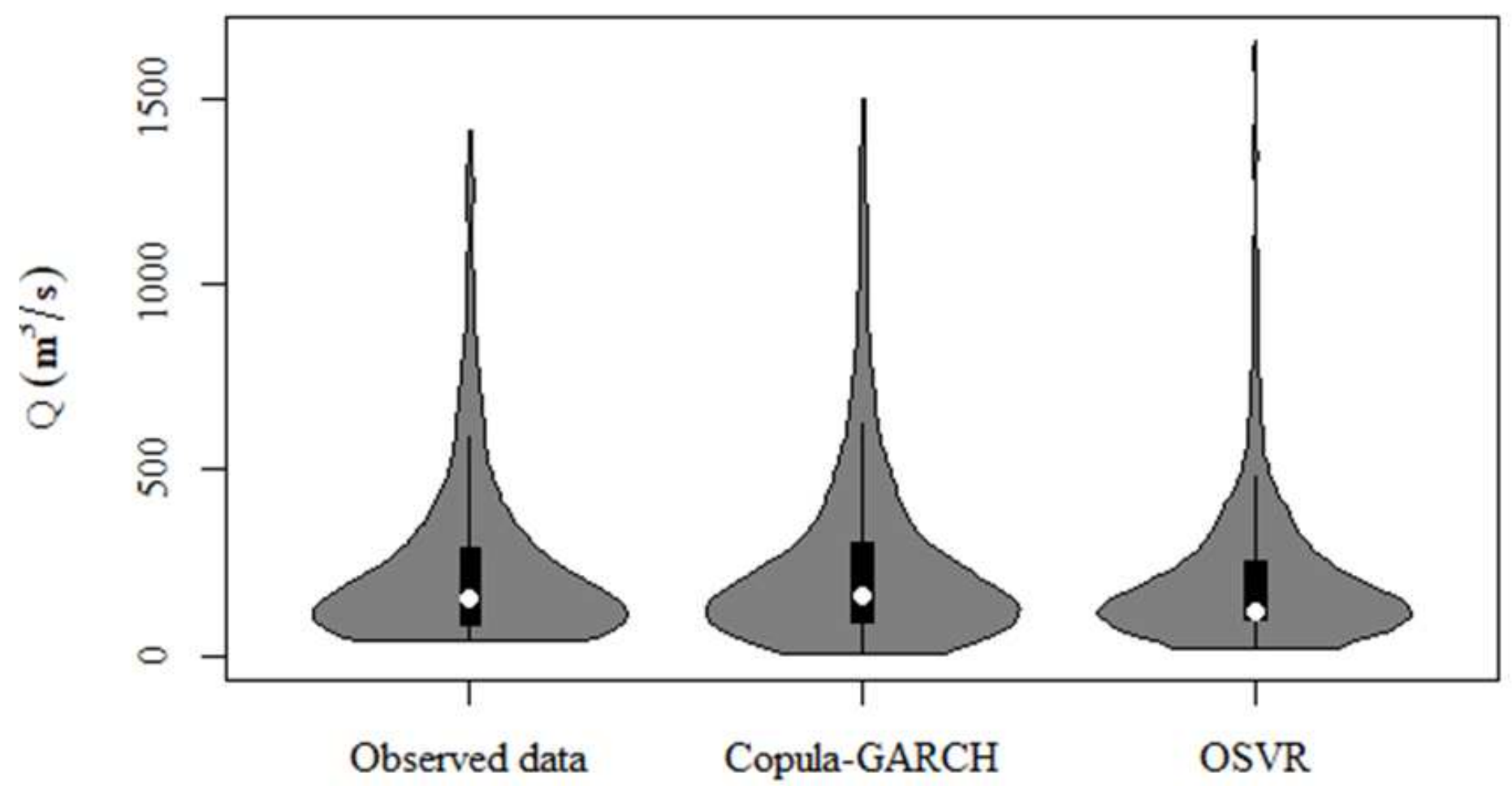

Figure 9

Violin plot of MMD (m3/s) series in the Talezang hydrometric station and corresponding simulated series by Copula-GARCH and OSVR models. 


\section{Taylor Diagram}

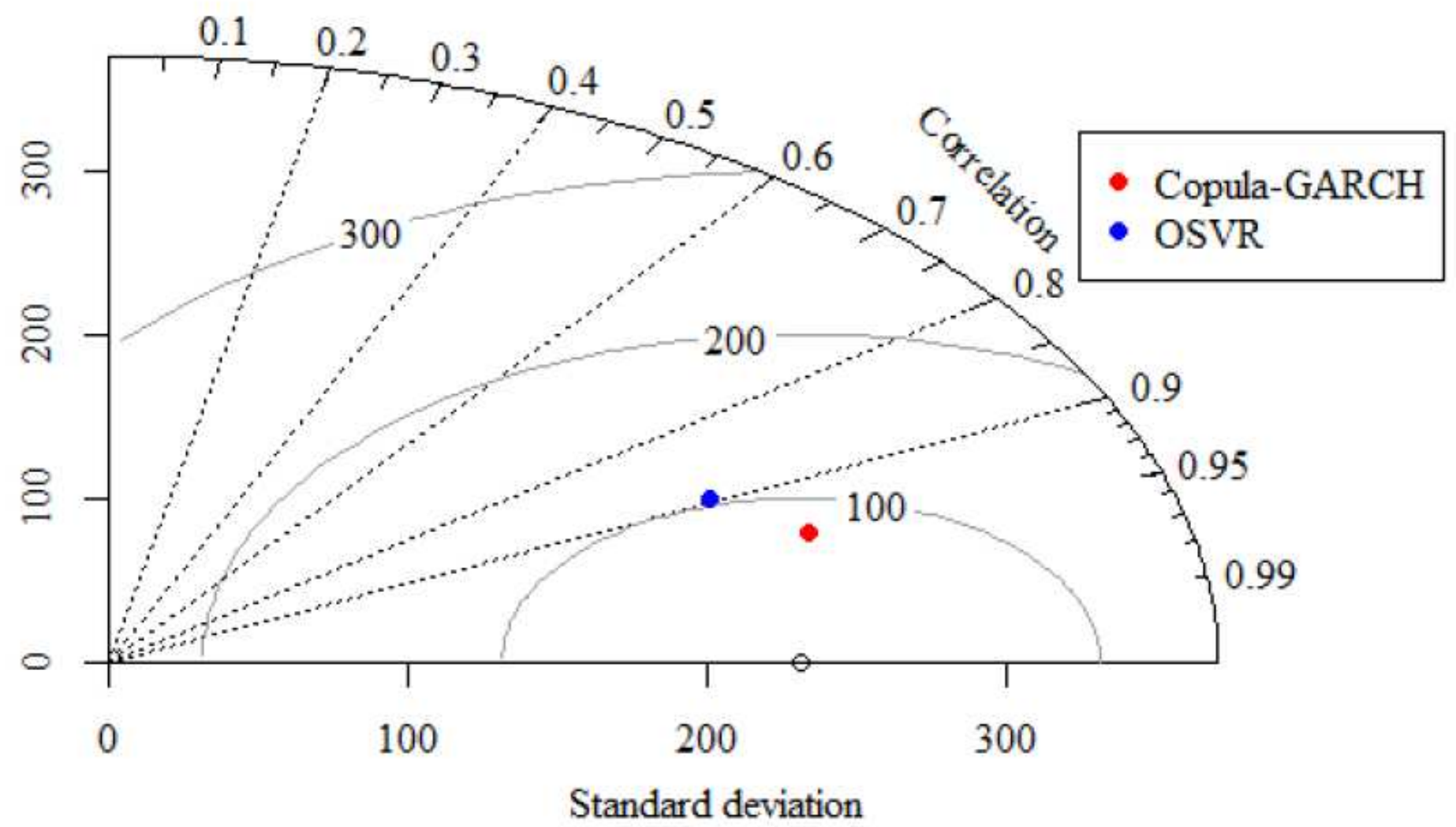

Figure 10

Taylor Diagram of MMD (m3/s) and corresponding simulated series using OSVR and Copula-GARCH models 